\section{WHAT IS NOT IN THE ARCHIVE}

\section{TEACHING TELEVISION HISTORY IN THE DIGITAL HUMANITIES ERA}

\author{
Jasmijn Van Gorp \\ Utrecht University \\ Muntstraat 2a \\ 3512 EV Utrecht \\ The Netherlands \\ j.vangorp@uu.nl \\ Rosita Kiewik \\ Utrecht University \\ Muntstraat 2a \\ 3512 EV Utrecht \\ The Netherlands
}

rosita.rose.kiewik@gmail.com

\begin{abstract}
This article discusses the pedagogy and outcome of a new assignment we introduced in the course 'Television History Online' at Utrecht University. We assigned the students the task to build a canon of a genre of Dutch television and create a video poster on the EUscreen portal consisting of clips that represent part of their canon. In our pedagogy, we argue that it is important to draw students' attention to what is missing in the archive. Therefore, we offered the students the possibility to replace illegal clips with blue videos and clips of non-digital or lost television programmes with black videos in their video poster. We found evidence for an availability paradox: students let not only their selection of programmes and clips, but also the demarcation of their entire canon, be reliant on the digital, online availability of audiovisual material. At the same time, they explicitly did not want to be restricted by unavailability. In this article we stress the need for more open data and the importance of training digital literacy skills.
\end{abstract}

Keywords: copyright, teaching, MyEUscreen, Digital Humanities, classroom, digital tool criticism, digital literacy.

\section{Introduction}

Before the VCR, scholars were fully dependent on television broadcasts and archival viewing services for their research. With the introduction of the VCR in the 1970s, it became possible for non-professionals to record and play 
back television programmes. ${ }^{1}$ In the late 1990s, the arrival of the DVD further improved the accessibility of television material for television scholarship. Brunsdon, for instance, argued excitedly that the release of television programmes on DVD affected both the availability of study texts and the labor of scholars. ${ }^{2}$ It was no longer necessary to describe entire sequences to the reader, and to judge how much detail is needed: "Writing about television that is available is different than writing about the ephemeral and inaccessible", she states. ${ }^{3}$

Currently, a similar kind of excitement surrounds the possibilities offered by the digital humanities. Television programmes and contextual material have been digitized, cross-linked and made searchable through a variety of digital tools such as the ones provided by EUscreen, AVResearcherXL ${ }^{4}$ and the Dutch project CLARIAH Media Suite $^{5}$. Moreover, YouTube and Vimeo, as well as VOD platforms enable instant watching, analysis, embedding and re-mixing. John Ellis anticipated on this development as 'the era of plenty': "It is foreseen as an era in which television programmes (or, as they will be known, 'content' or 'product') will be accessible through a variety of technologies, the sum of which will give consumers the new phenomenon of 'television on demand' as well as 'interactive television."'6

Following calls by i.a., McPherson, key questions emerged referring to how these new technologies in the 'era of plenty' affect the labour of media researchers, what skills are needed to cope with these new possibilities and whether and how pedagogies for television history need to be changed. ${ }^{7}$ It is the latter question which we would like to address in this article: how can we teach a new generation of students 'digital literacy' in order to do television historiography in the digital humanities era? Current undergraduate and graduate students are digital natives: they grew up with the internet and are used to googling everything. They have Google as (re)search standard, as Mahony \& Pierazzo argued. ${ }^{8}$

In this article, we introduce and discuss a model of pedagogy for digital television historiography aimed at the current generation of Digital Natives, with a focus on teaching about the availability of and access to audiovisual content in the Netherlands. Case in point is a new assignment for the undergraduate course Television History Online on Dutch television history at Utrecht University. To underpin the learning goals of the assignment, we argue that it is necessary to draw students' attention to what is not digitally available and accessible in the archive. In the next sections, we first outline our pedagogy of focusing on what is not available, then we discuss the context of the course and the assignment, followed by a discussion on how the students dealt with the new assignment.

\section{Towards a Pedagogy for Teaching Television History}

In the digital humanities, there is growing scholarship on pedagogies. The anthology Digital Humanities Pedagogy: Practices, Principles and Politics (2012) for instance addresses ways to incorporate digital technologies in teaching. ${ }^{9}$ An important new initiative in the field of media studies are the teaching dossiers as set up by Cinema Journal as

\footnotetext{
1 Jonathan Bignell 'Citing the Classics: Constructing British Television Drama History in Publishing and Pedagogy,' in Helen Wheatley, ed, Re-Viewing Television History: Critical Issues in Television Historiography, I.B. Tauris, 2007, 27-39, p. 31.

2 Charlotte Brunsdon, 'Television Criticism and the Transformation of the Archive,' Television \& New Media 10, 1, 2009, $28-30$, p. 29.

3 Ibid., p. 29.

4 Jasmijn Van Gorp, Sonja de Leeuw, Justin van Wees and Bouke Huurnink (2015), 'Digital Media Archaeology - Digging into the Digital Tool AVResearcherXL,' VIEW: Journal of European Television History and Culture, 4, 7, 2015, 38-53.

5 CLARIAH MediaSuite is building state-of-the-art tools for a.o. annotation, visualisation and exploration for different, heterogeneous types of content such as broadcasts, broadcast magazines and newspapers. See http://mediasuite.clariah.nl

6 John Ellis, Seeing things. Television in the Age of Uncertainty, I.B. Tauris, 2000, p. 37.

7 Tara McPherson (2009), Introduction: Media Studies and the Digital Humanities, Cinema Journal, 48 (2), $119-123$

8 Simon Mahony and Elena Pierazzo, 'Teaching Skills or Teaching Methodology?,' in Brett D. Hirsch, ed, Digital Humanities Pedagogy: Practices, Principles and Politics, Open Book Publishers, 2012, 217-18.

9 Brett D. Hirsch, ed, Digital Humanities Pedagogy: Practices, Principles And Politics, Open Book Publishers, 2012.
} 
well as the journal's 'In focus' sections ${ }^{10}$. At the time of writing, the dossiers are primarily focusing on the US context and also on teaching in the classroom. Given the increasing amount of available data and tools, much more scholarship needs to be done on how digital sources and tools affect pedagogy, and especially on how they affect research methods. ${ }^{11}$

In television studies, a lot has been written about pedagogies for television historiography. ${ }^{12}$ The existing literature focuses primarily on 'analogue' television historiography. Historiography also implies the making of decisions and selections. One important step in this selection process is the retrieval of those motivated choices. ${ }^{13}$ As such, television historiography relies on the critical and motivated selection of sources to be used within a research project. An important quality or skill in this data gathering process (and research in general) is 'reflexivity'. Bignell, for instance, refers to the reflexivity of television pedagogy and publication as "situated rhetorical practices", which raises questions of methodology. ${ }^{14} \mathrm{He}$ points at the iterative processes of citations and selected items in which once an item (television programme/author) has been selected or mentioned as being important. Other works of pedagogy tend to select the same item, which eventually ends up in a small selection of often cited items and excludes others. In the same line of thinking, Lynn Spigel states that it is important to teach students about different programmes than the ones they already know from watching television. ${ }^{15}$

Therefore, television history lecturers have to train students in how they can be reflective of their own selection criteria on one hand and the selection mechanisms of the archive, institutes and the digital interfaces on the other hand. A common perspective in television studies, based on Foucault's work, ${ }^{16}$ is that archives as sites of knowledge production define the conditions of possibility that shape what stories can be told. Spigel uses Foucault in arguing why it is important to look at what is not there:

But if the archive is just a representation of the past, then we always need to ask what lies outside the archive. What isn't arranged and collected there? What can't the archive contain? ${ }^{17}$

In order to assess and understand what is available and what is absent, and especially why an item is present or absent, contextual information is needed. As Janet Thumin points out, what is available has been pre-selected according to criteria oftentimes not available to the researcher who is using the material as a resource. ${ }^{18}$ Moreover, when it comes to early television, a lot of programmes are gone forever, for instance because the reels have been reused for recording other programmes since at that point in time there was not yet a culture of archiving 'for the future', let alone archiving for the purpose of academic research. ${ }^{19}$ Taylor explains that television companies "never saw themselves as archivers of the material they created - unless the material could be rebroadcast or sold to other companies." ${ }^{20}$ For researchers, it is difficult to trace a lost or non-preserved broadcast or to pinpoint the reasons why a broadcast is no longer available.

10 See In Focus on 'Digital Scholarship and Pedagogy,' Cinema Journal 2009, 48, 2. The Cinema Journal Teaching Dossiers are appearing online on http://www.teachingmedia.org

11 See Mahony and Pierazzo's call 'there is a need for teaching methodological approaches and not simply technological skills,' ibid., p. 215.

12 E.g. John Corner, 'Finding data, reading patterns, telling stories: issues in the historiography of television,' Media, Culture and Society, 25, 2, 2003, 273-280; Bignell, 2007.

13 Michele Hilmes, 'Introduction,' in Michele Hilmes, ed, The Television History Book, BFI Publishing, 2003, p. viii.

14 Jonathan Bignell, 'Exemplarity, pedagogy and television history,' New Review of Film and Television Studies 3, 1, 2005, 15-32.

15 Spigel 2005, p. 90.

16 Michel Foucault, The archeology of knowledge, Pantheon, 1972.

17 Spigel, 2005.

18 Janet Thumim, 'Mrs Knight Must Be Balanced: Methodological Problems in Researching Early British Television,' in Gill Branston, Stuart Allan and Cyntia Carter, eds, News, Gender and Power, Routledge, 1998, 91-104.

19 As Spigel argues we know very little why programmes have been saved and why they have been lost. Lynn Spigel, 'Our TV Heritage: Television, the Archive and the Reasons for Preservation,' in Janet Wasko, ed, A Companion to Television, 2005, 67-102, p. 68.

20 Philip M. Taylor, 'Television and the Future Historian,' in Graham Roberts and Philip M.Taylor, eds, The Historian, Television and Television History, University of Luton Press, 2001, 171-177, p. 174-175. 
This issue of presence and quality of preservation, documentation and contextualisation of broadcasts conflicts with the abundant digital data and tools that have recently become available. While the digital turn has allowed for easier access to and use of digital data, the same turn also shows that crucial data is missing. Juhasz and Prelinger both show how the most popular platform for free online videos, YouTube, is regarded as an "ideal form of an archive" by the general audience. ${ }^{21}$ Prelinger argues that YouTube is such an attractive archive to the public, because, amongst other reasons, it appears to be a complete collection and because it offers instantaneous access with very few limitations. ${ }^{22}$ But, in practice, they argue that YouTube is not very useful for research and teaching because context information is missing. Juhasz explains the 'messiness' of YouTube as follows: "While its millions of users would be well served by a good archivist or two, in its calculated failings YouTube signals that it is [...] not a place within which to seriously research or study". ${ }^{23}$ However, students remain very much attracted to YouTube, and use it a primary source when looking for audiovisual content online..$^{24}$

Following this line of reasoning, it is the dichotomy between 'plentiness versus scarcity' - what is in the (digital) archive and what is not - that is underlying our pedagogy. Students should learn to question the role of digital access and digital availability in television historiography. When training students in reflective skills for television historiography, we argue, it is important to focus their attention on their selection process in relation to issues of availability and accessibility. More in particular, we would like to devote considerable attention to the inaccessibility and lack of availability of material: of what is absent, what is missing. In the next section, we outline how we translated this pedagogy into an assignment.

\section{The Assignment: Building a Canon}

The undergraduate course Television History Online at Utrecht University was launched in 2014. In 2016 we decided to reframe the course in a more methodological course and focus on the first phase of doing research: selecting material. The course lasted 10 weeks and had two assignments. The first assignment, the midterm, is the subject of discussion in this article. ${ }^{25}$ Since selection was the main topic of the course, we decided to focus on a common practice of an (iterative) selection processes: the building of a national canon or - in our case - the building of a Dutch television canon. ${ }^{26}$ According to Ellis, a canon is regarded as having "enduring value" and therefore, "any good canon will also expose its biases and its underlying rationales." 27 In addition, we decided to incorporate what students do on a daily basis - browsing through YouTube and online video platforms - into pedagogical material. This resulted in the following assignment.

21 'Ideal form of archive' is a quote from Rick Prelinger, 'The Appearance of Archives' in Pelle Snickars and Patrick Vonderau, eds, The YouTube Reader, National Library of Sweden, 2009, 268-274, p. 168.

22 Ibidem, p. 270-272.

23 Alexandra Juhasz, 'Learning the Five Lessons of YouTube: After Trying to Teach There, I Don't Believe the Hype,' Cinema Journal 48, 2, 2009, 145-150, p. 149.

24 Statement based a.o. on a survey taken at the very start of our course in 2016, which is retaken with the course of 2017 . Both surveys yielded similar results: YouTube is the most consulted repository for audiovisual clips by the students that responded on the survey.

25 The second assignment is a final paper. Our students track the selected Dutch television programmes and clips for their video poster with tools and compare them in a similar fashion as Alan McKee. Alan McKee compares YouTube with the National Archive in Australia, and hence provides a good overview of how YouTube can be used for research. See Alan McKee, 'YouTube versus the National Film and Sound Archive: Which is the More Useful Resource for Historians of Austrialian Television?,' Television \& New Media 12, 2, 2011, 154-173.

26 In the course we spent two sessions to contesting the concept of canon and canonization. Besides Ellis (2007), the students read and discussed Bignell (2007) and the introduction of Wheatley's book (2007). One of the first in-class assignments was to select one existing canon (e.g. history book, DVD-box, tv-documentary, online exhibition) and critically deconstruct the concept of 'canon'.

27 John Ellis, 'Is it Possible to Construct a Canon of Television Programmes? Immanent Reading versus Textual-historicism,' in Helen Wheatley, ed, Re-viewing Television History: Critical Issues in Television Historiography, I.B.Tauris, 2007, 15-26, p. 15 
J. Van Gorp and R. Kiewik, What Is Not in the Archive

Students had to constitute a canon of a genre in Dutch television and present clips from this canon in an online video poster builder on EUscreen (MyEUscreen). ${ }^{28}$ They had to create a canon of eight television programmes, and from four of those eight programmes students had to select a short video that would, for whatever reason they deemed justifiable, represent this programme in their video poster.

Importantly, to improve their critical reflection skills, we let students replace clips that would otherwise be missing with a video indicating the reason for replacement. The students could select a video that infringed copyrights and replace it by a blue video reading 'This videoclip does not belong to the public domain and/or does not have a Creative Commons License' (see Video 1). If the students wanted to choose a video of a television programme that did not survive or that had no digital, online available content, students could embed a black video reading 'This videoclip is not available' (see Video 2). In class, we showed how they can assess copyrights and discussed 'open images' and the working of Creative Commons licenses. We also provided the students with a fictional video poster about the genre of 'cat television' (see Figure 1) as an example of what a video poster could look like.

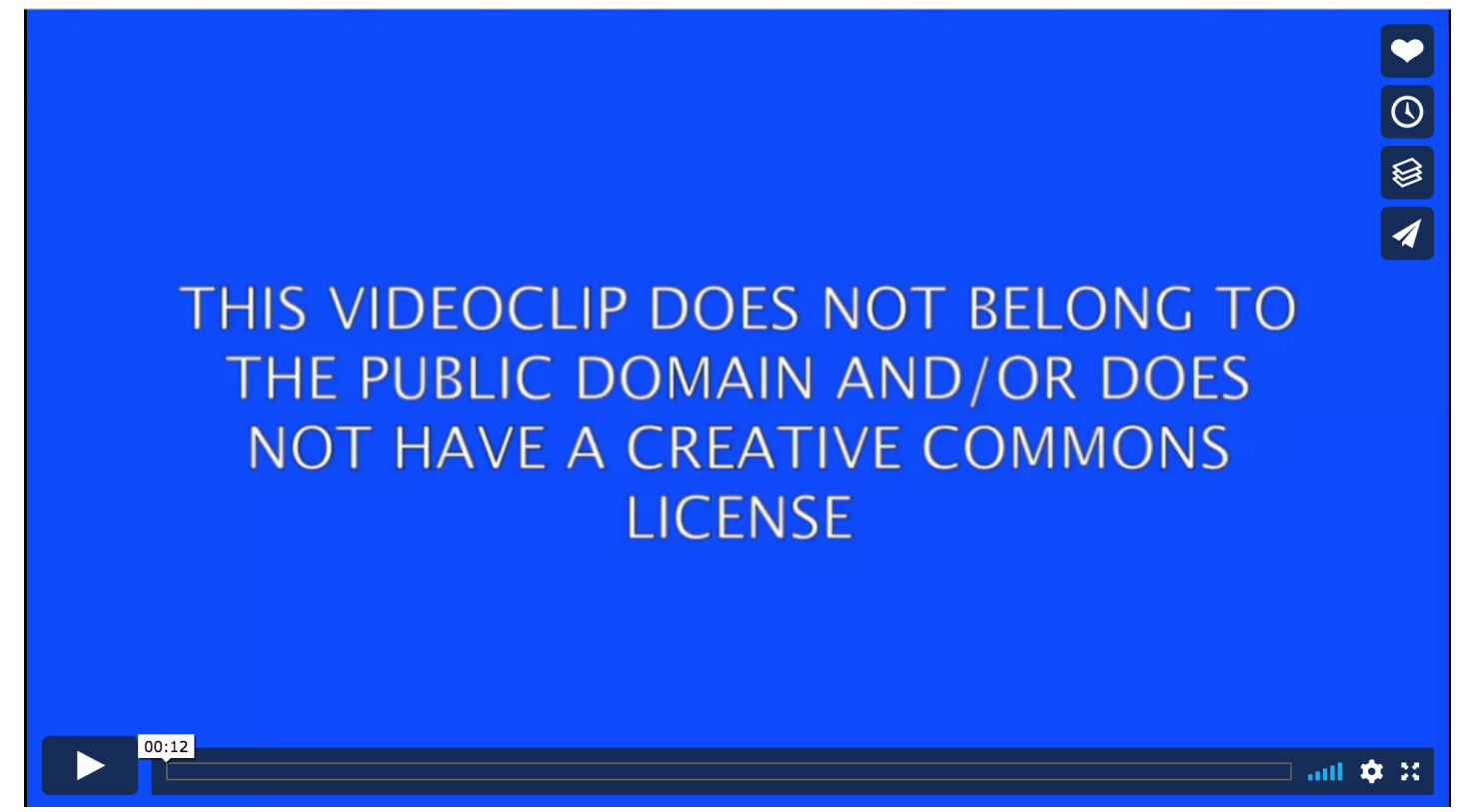

Video 1. The blue video that could be used to replace YouTube or Vimeo videos with copyright infringements. Go to the online version of this article to watch the video.

By using this additional guideline of blue and black videos, we wanted to investigate how students deal with missing videos and how they assess copyright infringements on, for example, YouTube. As Berliner notices in a Cinema Journal Teaching Dossier it is of utmost importance that an assignment requires students to be simultaneously reflective about form and content in their work. ${ }^{29}$ We tried to accomplish this by letting students make a visual presentation with the EUscreen video poster builder on MyEUscreen as well as letting them write a reflection paper explaining their decisions and their work process. Through the creative assignment of making a video poster, students were forced to think about their choices in four ways: (1) by the very choice of genre, (2) by the use of black and blue videos to replace non-existing or illegal video clips while making the video poster, (3) by an in-class poster presentation during which students could inquire about each other's choices, (4) by writing a paper in which students substantiated their choices. 


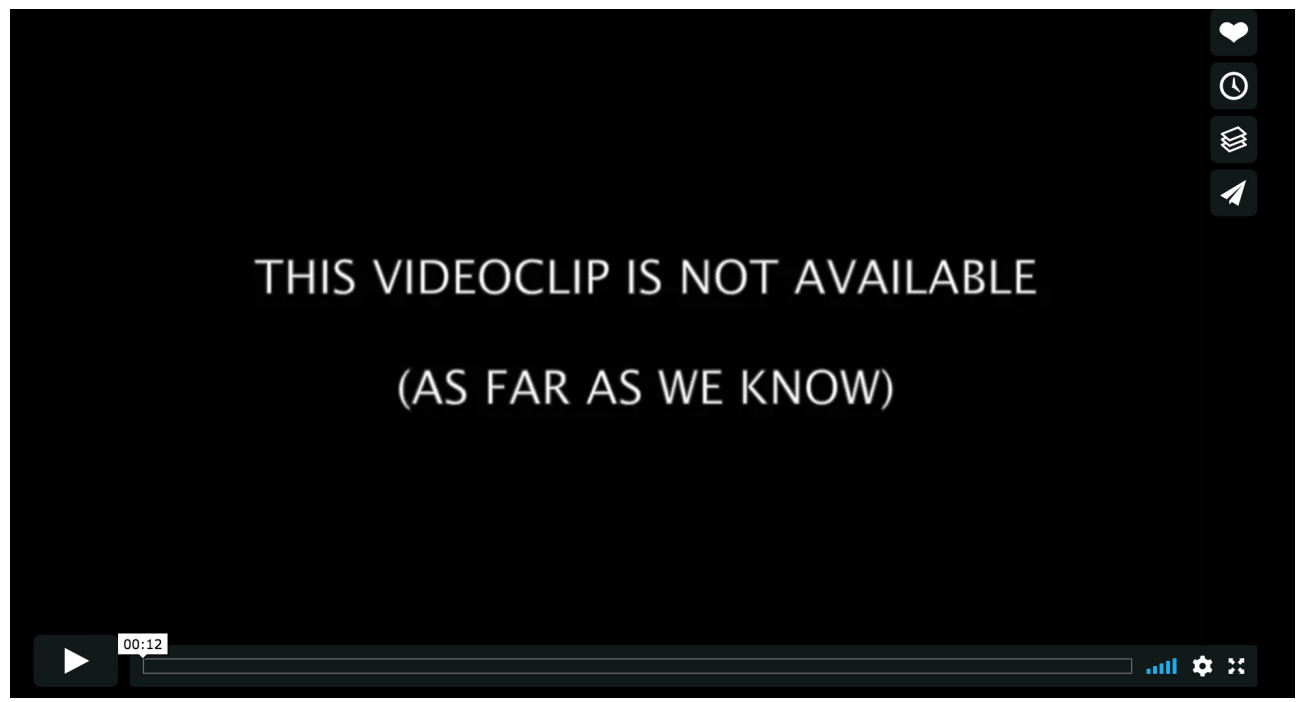

Video 2. The black video that could be used for digitally unavailable videos. Go to the online version of this article to watch the video.

\section{A canon of Dutch "cat television"}

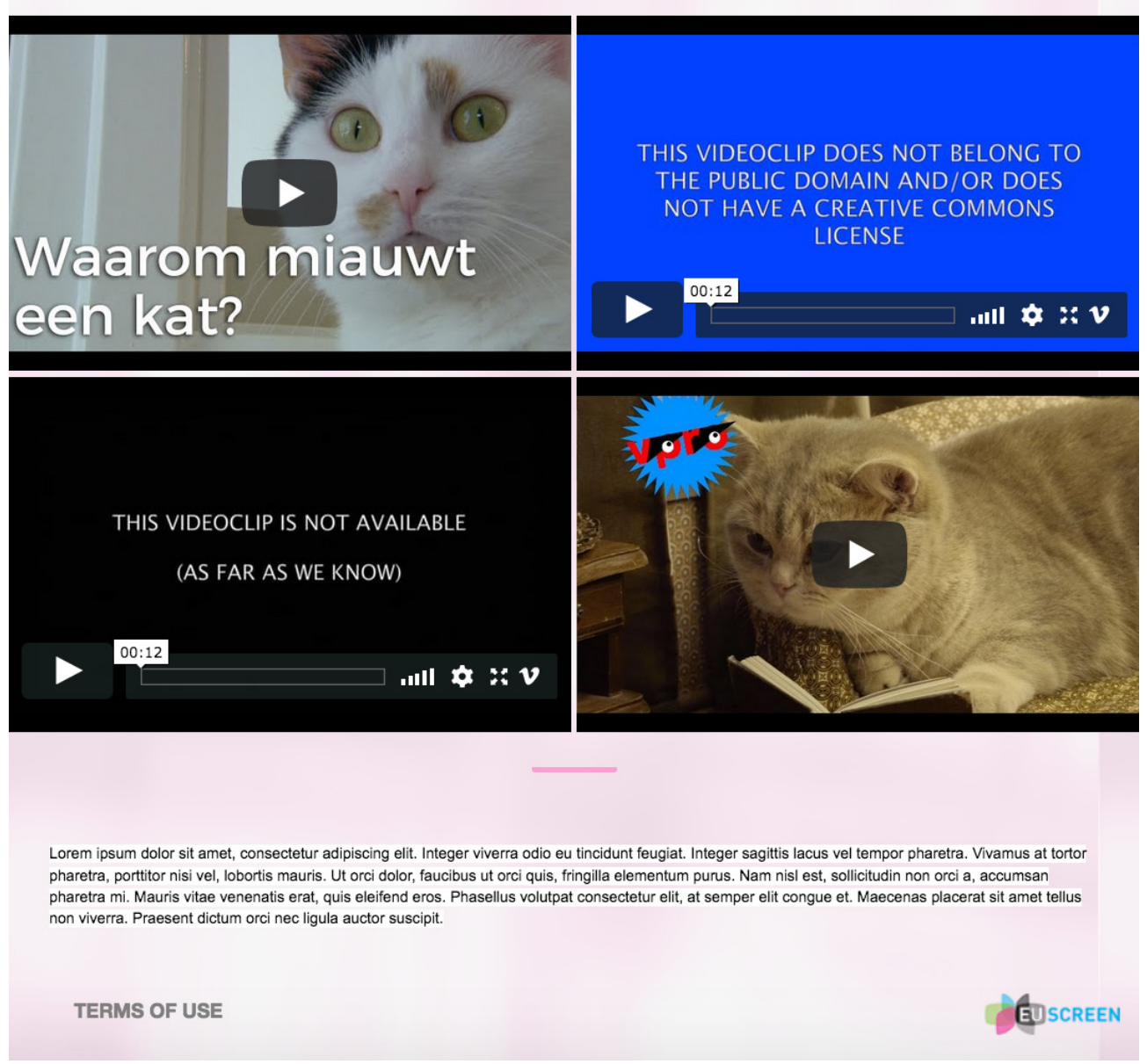

Figure 1. Fictional (unpublished) video poster on the genre of 'cat television' provided to the students as an example. 
There were 42 students enrolled in the course, most of them studying television as Major, while others majored in Language, Communication and History. Assignments were made in groups of two or three students. We had a total of 20 groups, and therefore 20 video posters, presentations and papers, divided between two classes. ${ }^{30}$ All presentations were observed by one of the researchers, who was free of grading duties during observation since the presentations did not receive a grade. Observations were focused on the selection process, the corpus or canon creation (here we draw a parallel between the methodology of data gathering and the concept of canon), and the argumentation behind those as presented by the students. During observation the researcher wrote down any information the students provided about their choices, the material that they looked for and did or did not find, the material that they chose to use for their assignment, and the observations they made during the entire process. ${ }^{31}$ The content of the video posters and papers, as well as our notes from the students' in-class presentations and discussions, have been qualitatively analyzed by means of a grounded-theory approach. ${ }^{32}$ The data was anonymised, and analysed for recurring main themes. These main themes were added to the data as categorical labels which we shall discuss in the following chapter. ${ }^{33}$

In the next section we discuss the assignments by following the chronology of the students' research process. We look at how students carried out the assignment and to what extent we found instances of reflection and increased awareness of that which is missing.

\section{Selection Procedures of Genre and Canon Construction}

We will first look at the construction of the canon or the exploration phase: the definition demarcating the canon, and the strategies used for the construction of the canon itself. First, the students had to select a genre. They were allowed to look at subgenres within genres and we encouraged them to be creative when demarcating a genre. We observed that most student groups played it rather 'safely' in their choice of genres and made selections based on their own genre preferences. They came up with the following, often overlapping genres for their canon(ization):

- talk shows (2 groups)

- game shows (2 groups)

- travel TV shows (2 groups)

- educational children's TV shows (2 groups)

- children's TV shows (1 group)

- children's TV series (1 group)

- children's drama (1 group)

- sports TV (1 group)

- dating shows (1 group)

- talent competition shows (1 group)

- puppet TV shows (1 group)

30 Two students from one group did not give permission for the use of their data, therefore our analysis is based on 19 presentations, video posters, and papers.

31 Our position towards the data sources during the time of data collection was twofold: we had both the role of teachers and of researchers. We therefore made a very clear decision to put pedagogy first - since our students should, of course, not disadvantage from the course they are enrolled in being an object of research. We discussed and shared our findings with them, so that they could reflect on these ideas and use them in the follow up assignment. Note: this second, follow up assignment is not part of this research article. We plan to publish the course manual online, so readers can find both assignments and the reader there.

32 Anselm Strauss and Juliet Corbin, Basics of qualitative research: Grounded theory procedures and techniques, Sage, 1990.

33 Since our data is based on the students' assignments, we asked the students' permission for the use of the material. Informed consent was asked a few weeks into the course, after the students had given their presentations, because, as mentioned above, we wanted the pedagogy of the course to prevail over the collection of data and we wanted to prevent putting extra pressure on the students. 
- food-and-cooking TV shows (1 group)

- $\operatorname{sitcom~(1~group)~}$

- royal family on TV (1 group)

- commercials (1 group)

\subsection{Exploring the Genre}

After choosing a genre, students had to further define the framework for their canon and construct the canon itself. Strategies for exploring and forming a short list of television programmes that might become part of the canon diverged between groups of students. Some students chose to first look at literature about Dutch television, either academic or popular, whereas others instantly reached out for digital search tools to find out which television programmes could be found that were connected to their genre. One group of students also stated that they combined the use of tools with the use of their own recollection of television programmes. In the exploratory phase of the canon construction all students used different digital tools and sources side by side.

Digital tools were the main and most decisive source of information for the students, since they looked for television programmes that were digitally available and were preferably also usable for the creation of a video poster on the EUscreen poster building platform (i.e. available on either EUscreen, YouTube or Vimeo and therefore could be embedded in the video poster). Various online digital tools were used concurrently. One reason students gave for choosing this approach, was that the use of multiple digital tools while doing research is important, because the set of available audiovisual material and other data differs between tools.

Students also combined the use of digital tools that contain audiovisual material with the use of other - both digital and non-digital - sources to gain contextual information about the television programmes, since this information was deemed important. They realized that, although digital tools of the popular archives (e.g. YouTube, Vimeo) have great availability of audiovisual material, these tools categorize and describe material through popular indexing and therefore often lack contextual- or metadata information. ${ }^{34}$

\subsection{Canon Demarcation and Construction}

Most students stated that surviving audiovisual material made television programmes necessary to be shortlisted and taken into consideration for inclusion into their canon. Survival of a television programme was given even more emphasis by some groups who decided that institutional curation by the National Institute of Sound and Vision (NISV), either in the institute's database, on its Wiki, or in its museum (called 'Experience'), would be the starting point for their canon construction. Availability, in this way, became a crucial part of the selection process.

For the construction of their definitive canon, the students all focused their attention on television programmes that had audiovisual material available. Sometimes this focus was explicitly based on the deemed importance of the survival of audiovisual material in archives. Survival was used as an argument to show the importance or value of a specific television programme: if it was archived, apparently someone had considered it worth archiving, so perhaps the television programme would also be worthy of inclusion in the canon. In other cases this focus in the selection process on survival occurred without any given reason. 
The regarded importance of availability sometimes determined the selection criteria for the canon construction so heavily, that students even based the demarcation of their canon on it. This happened for example, when some students decided to only include television programmes from public broadcasters in their canon, because there was less audiovisual material available, accessible and free of copyright infringement issues from commercial broadcasters than it is from public broadcasters. A different group of students, for the same reason, decided to create a canon that was only representative of the era in which commercial television broadcasters did not yet exist in the Netherlands.

Students also emphasized the importance of availability of audio visual content from a television programme as a primary source for researchers, because it allows them to judge the material for themselves instead of relying on secondary sources. However, none of the groups of students based their selection for the canon on their own viewing of the material. At the same time, not one group of students included a television programme in their canon that had no survival of audiovisual material. From the get-go, students focused their attention on what was available and accessible in the archive, whether that was an institutional or a popular archive, and thereby they omitted all that was not in the archive. We would like to explicitly note here that the limited time that was available for the students to complete the assignment - namely, three weeks - might have played a part in the students' decision making process, since watching, analysing and comparing audio visual material, or exploring that which is not in the archive, are both time consuming strategies for canon construction.

\section{Video Selection for Video Poster}

A first presentation of the canon was done in class by making use of video posters that were created with the EUscreen video poster builder. Students were instructed to explain and support all of their decisions. Some students had clear selection criteria to decide which television programmes were included in the video poster. A few groups of students chose programmes based on their popularity, either by looking at contextual sources such as viewing rates and mentions in literature about Dutch television history, or by looking at the amount of views that videos of the television programmes had within the search tool of the popular archive (e.g. YouTube, Vimeo, etc.) that they used. Other students based their selection on the availability of audiovisual material that allowed clips to be used in the video poster.

After selecting the four television programmes,, the selection of the videos that were to be included in the video poster mostly happened by applying a similar logic: the students selected videos that were available and accessible to them. Aside from availability, most students found it important that the content of the chosen videos was - in some way or another - a good representation of the television programmes. Figure 2 shows the video posters as they were presented in class and handed in by the students. ${ }^{35}$

\subsection{Black and BIue Videos}

Unavailable material was not at all taken into consideration for the assignment. Therefore, black videos were never needed. ${ }^{36}$ Students seemed disinclined to consider material that was not available to them. Students used a selection

35 The fourth poster on the lower row was made by a single student and therefore consists of two instead of four clips. The fifth poster on the lower row was made by the students who did not give permission for the full inclusion of their assignment in our research and is therefore blurred.

36 Note that a few students misunderstood the meaning of the black videos and used them in their video poster, while these were actually meant to be blue videos. The blue video was much easier to understand than the meaning of the black video. For usage of the black video, types of availability have been mixed up by the students: availability of the record, availability of the metadata, availability of a video and availability of the full range of programmes. 

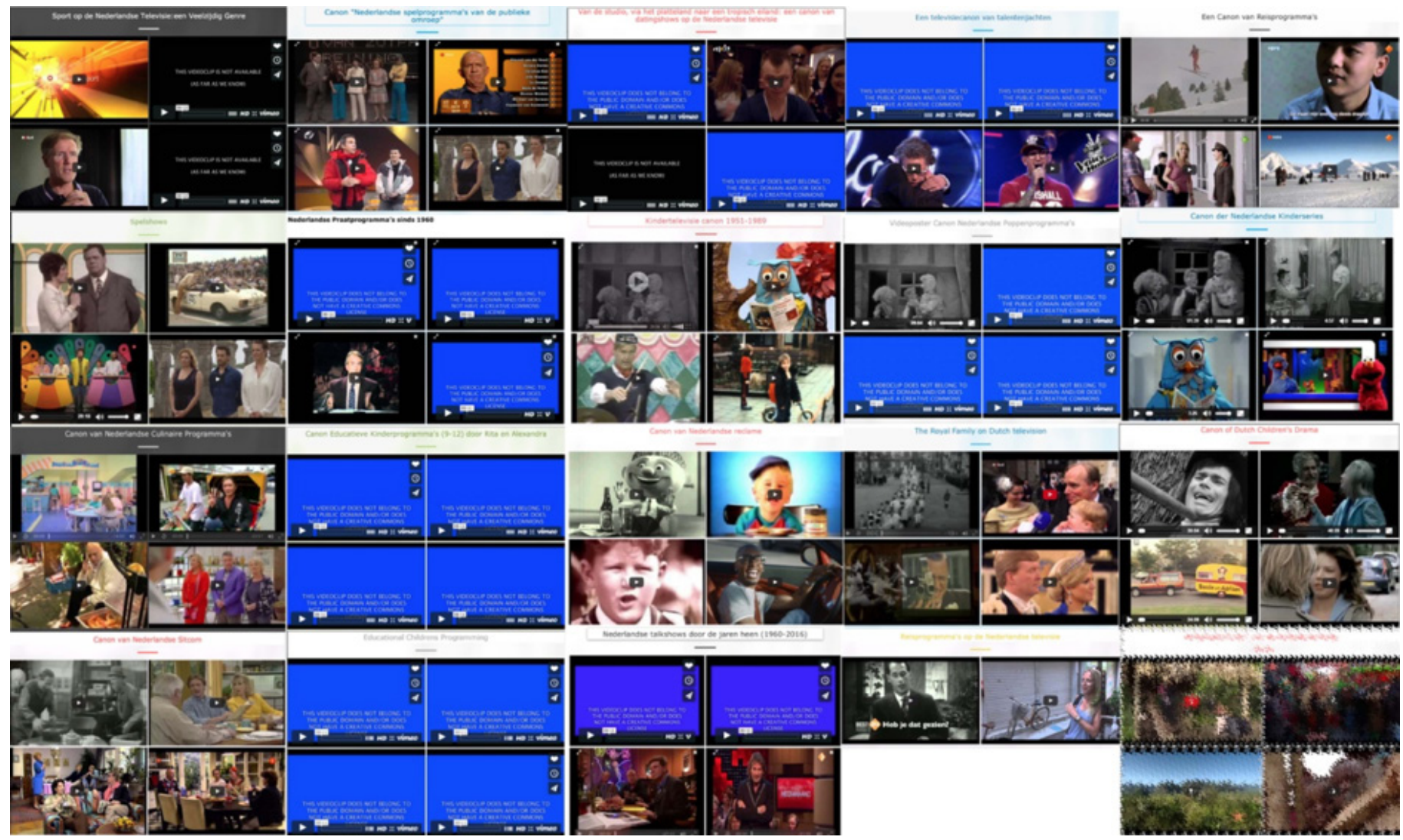

Figure 2. The video posters as presented in class and handed in by the students.

method that was often influenced by the prospective that their end product would have to be presented in class. They were, so to say, in a 'presentation mode' and argued that they chose to work with online available material, because this prevented the use of blue or black videos. Some students said:

We wanted to use a different clip in our video poster, but we could only find an illegal upload of it. So, since we wanted to show actual footage, we decided to choose another video instead. ${ }^{37}$

And, of course, students wondered: "What is the use of a video poster if you can not show any videos?"38

However, the poster presentation was not just dependent on issues of availability but also on copyright infringement issues. Some television programmes had audiovisual material available, but it was technically not accessible to the students for use in their video poster. For example, because material was only available on platforms that were copyright protected and were not compatible with MyEUscreen for embedding material in video posters (e.g. npo.nl, the Dutch public broadcasting website, or rtIxl.nl, the website of commercial broadcaster RTL Netherlands, etc.). Another reason was uploaded on the MyEUscreen compatible YouTube or Vimeo, but was not uploaded by the copyright holders.

Since most students put much emphasis on creating appealing, aesthetically pleasing video posters, they often attempted to find a way around these copyright infringement issues. One group of students, for example, did not want to be limited in their poster creation by unavailable, inaccessible or copyright infringing material, and therefore chose 
J. Van Gorp and R. Kiewik, What Is Not in the Archive

to use promotional videos in their video poster that were made and uploaded to YouTube by the production company or the broadcaster of the programme (i.e. a right holder).

As Figure 3 shows, eight out of twenty groups of students used blue or (wrongly used) black videos. Their motives for (not) using these videos varied. If material was not accessible free of copyrights, some students chose to embed a blue video instead of showing their chosen video, thus being able to still select the video of their choice without infringing copyrights. Other students chose to use audiovisual material that was not free of copyright infringement issues for their video poster and to show this material instead of using a black or blue video. Because they knew their work would not be published anyway, some of them did this because they wanted their video poster to be visually appealing. One student said: "If we would have used blue or black videos, our video poster would have looked bad. We think it looks unappealing." 39 Others ignored the copyright issue during the in-class presentation of the video poster, because they wanted to show actual footage of the television programme, and later inserted blue videos when they updated the video poster to hand it in for a grade. Some groups of students forgot to replace their copyright infringing videos with blue videos for the in-class presentation, and were reminded to do so during the presentation.

\subsection{Activist Motives}

Since for a lot of television programmes audiovisual material could not be found by the students, or it could only be found on YouTube and with copyright infringement issues, students in general stated that the limited amount of
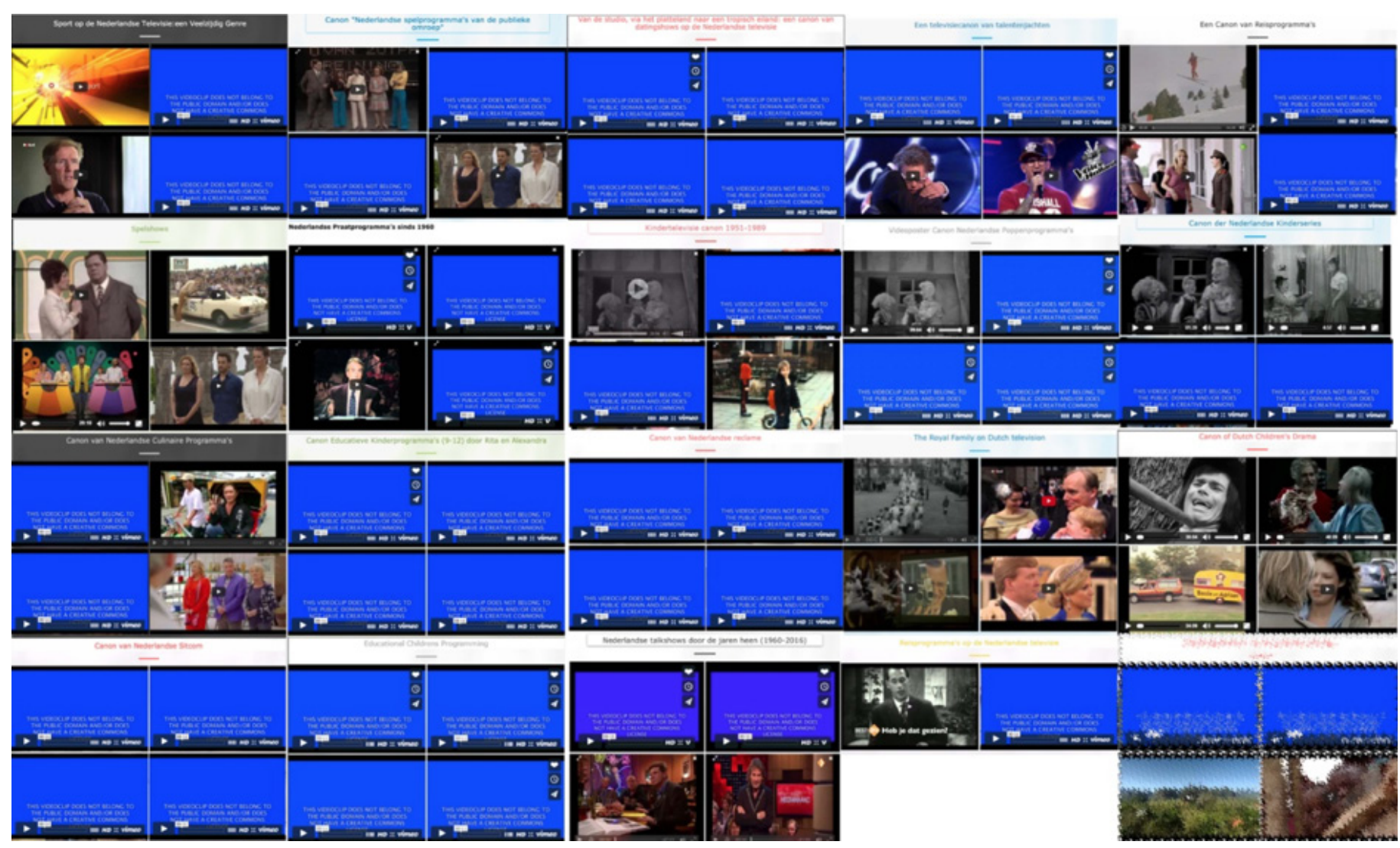

Figure 3. The video posters as corrected for use of blue and black screens according to the provided guidelines.

39 Student group 5, in-class presentation. 
available, easily accessible, open access audio visual material is one of the biggest challenges for television history research. Interestingly, some of our students subsequently even supported their choices for the use or non-use of blue videos with activist motives. Some of them used videos that were not free of copyright infringement issues as a form of protest towards the lack of available, accessible material that was free to use in an educational setting. Others specifically embedded the blue video instead of showing the video of their choice to make a statement about the lack of legally available and accessible audiovisual material. Students said the following about this activist reasoning:

We embedded some blue videos, because we wanted to show the lack of available, open access, audiovisual material. [...] These television programmes have run for a long time and therefore many episodes have been made, but still none of them were available for us to use. We feel that they should be. ${ }^{40}$

All in all, not all groups who used copyrighted audiovisual material inserted blue videos: if the students had strictly followed the guidelines, they should have used far more blue videos, as Figure 3 shows. The posters the students handed in contained twenty blue screens and three wrongly used black screens out of 78 screens in total, whereas the overview of the video posters as double-checked by us should have had 45 blue screens out of 78 screens.

\section{Conclusion: the Availability Paradoxb}

We implemented a new assignment in our course on Dutch television history to teach our students reflexivity on data gathering of audiovisual material with digital tools. Our findings indicate that the students trained their digital literacy skills in a number of ways. First, through the conscious action of replacing videos by blue or black videos, the students became more aware of their own selection process. Additionally, since they had to motivate their selection twice, i.e. during the in-class presentation and in their reflection paper, they learnt how to substantiate their selection criteria. During the in-class presentation, the students' peers and lecturers could help them in crystallizing their - by then often still tacit - motivation behind sections of their selection process. By the time students had to write and hand in their paper for grading, they had learnt to observe, identify and substantiate their own choices more thoroughly. The creative assignment of making video posters turned the abstract notion of 'critical reflection' on data gathering into a more playful practice. Therefore, we encourage other lecturers to implement creative assignments in their courses and to share these with fellow lecturers through online teaching platforms. ${ }^{41}$

In this era of plenty, or 'age of abundance' as Andreas Fickers calls it ${ }^{42}$, we found evidence for an 'availability paradox'. Students tended to base their selection criteria for the canon of television programmes and the selection of clips for the video poster on online availability, in order to not let unavailability of material restrict their work. In other words: although we gave students the freedom to not let their research be limited by availability by providing them with blue and black videos, they still stuck to the rationale of only selecting material which could be viewed online.

While an incredible amount of material is digitized and new technologies are made available continuously, the bottleneck for students and researchers remains copyrights restricting data gathering, analysis and publication processes. Students did not have to publish their posters on the EUscreen portal, so they could make use of material provided by YouTube and Vimeo for their assignment or use the blue and black videos to highlight unavailability. Nevertheless, interestingly and importantly, the raised awareness of the limited availability of audiovisual material for publication in a research context led to an upsurge of activism within our group of students. The lack of open data source material for online publication was regarded as one of the main challenges for research by the students. While making the assignment, students also became more aware of the gap in the amount of well archived and 
accessible material between public broadcasters and commercial broadcasters in the Dutch television landscape. They noted that commercial broadcasters should open up their archives for students and researchers, if they want to be part of the national television history.

It seems useful to think of further teaching possibilities based on the assignment discussed in this article, perhaps by including more types of data to enhance the writing of television histories. An alternative version of the assignment could be to let students replace programmes with no open streamed content with available digitized contextual information, e.g. viewing rates, set photos, reviews in broadcast magazines, photos of props, interviews with producers, scripts, scenarios and other production documents. This fits the advice by Mosely and Wheatley to 'critically reconstruct' and bring lost histories - in their case early women's television - back to life. ${ }^{43} \mathrm{~A}$ next important step would be to let students investigate the politics of missing data more extensively, by also conducting interviews with archivists and analysing archival policy documents and newspaper articles. ${ }^{44}$

The availability paradox emphasizes the importance of digital criticism and literacy: students, scholars and researchers need to be aware of how digital and online availability possibly influence their choices and therefore their research. It points to a need of an increased transparency in publications, in which researchers not only make clear what items they did not get access to and what they left out but also make more tangible in what ways these missing data sharpened their reflective processes, e.g. by means of a 'behind the scenes' article. ${ }^{45}$ In addition, the paradox underlines the need for more open source material for education and research and more digital tools to support researchers in finding their way through the massive amount of data.

\section{Biographies}

Jasmijn Van Gorp is assistant professor Television and Digital Culture at Utrecht University, the Netherlands. She is part of the core team of the Media Studies and Audiovisual Data work package of the Dutch infrastructure project CLARIAH, which developed the Media Suite (http://mediasuite.clariah.nl). In addition, she is co-chair of the Special Interest Group of Digital Humanities and Videographic Criticism of the Society for Cinema and Media Studies.

Rosita Kiewik is a freelance researcher, editor and reporter. She holds an MA degree in media studies, worked as a researcher within the Media Studies and Audiovisual Data work package of the Dutch infrastructure project CLARIAH, and was lecturer at the Department of Media and Culture Studies at Utrecht University.

\section{Acknow ledge ment}

The research for this article was made possible by the CLARIAH-CORE project financed by NWO (www.clariah.nl).

43 Rachel Moseley and Helen Wheatley, 'Is Archiving a Feminist Issue? Historical Research and the Past, Present, and Future of Television Studies,' Cinema Journal 47, 3, 2008, 152-158.

44 A good example of the politics of missing data is the research on archival representation of Moslim guest workers by Andrea Meuzelaar. See Andrea Meuzelaar, 'From Single Male Guest Worker to Muslim: an Archeaology of Iterating Archival Footage on Dutch Television', NECSUS European Journal of Media Studies, Spring issue 2016.

45 See e.g. this 'behind the scenes' article on archival research in the pre-digital era: Denise J. Youngblood, 'Film Research in Moscow, 1995,' Historical Journal of Film, Radio and Television, 15, 4, 1995, 563-568, DOI: 10.1080/01439689500260421. 